\title{
High mobility group box 1 protein attenuates myocardial ischemia reperfusion injury via inhibition of the p38 mitogen-activated protein kinase signaling pathway
}

\author{
YAN-HONG ZHOU* ${ }^{*}$ QIAN-FENG HAN**, LAN-HUA WANG, TAO LIU, XIAO-YAN MENG, \\ LEI WU, TAI LI, YUE-RU JIAO, HENG-CHEN YAO and DE-YONG ZHANG \\ Department of Cardiology, Liaocheng People's Hospital Affiliated to Shandong University and \\ Clinical School of Taishan Medical University, Liaocheng, Shandong 252000, P.R. China
}

Received July 4, 2016; Accepted April 28, 2017

DOI: $10.3892 /$ etm.2017.4653

\begin{abstract}
The present study aimed to determine the effects of high mobility group box 1 protein (HMGB1) on myocardial ischemia reperfusion (I/R) injury in rats following acute myocardial ischemia and investigate the underlying molecular mechanisms of these effects. Male Wistar rats were randomly divided into the following groups ( $\mathrm{n}=10 / \mathrm{group})$ : Sham operation; I/R; HMGB50 (50 ng/kg HMGB1 before I/R); HMGB100 (100 ng/kg HMGB1 before I/R); and HMGB200 (200 ng/kg HMGB1 before I/R). Serum cardiac troponin I (cTnI), interleukin (IL)-6 and tumor necrosis factor (TNF)- $\alpha$ levels were subsequently measured. Myocardial levels of malondialdehyde (MDA) and superoxide dismutase (SOD) were also determined. Myocardial infarction size (IS) was determined by 2,3,5-triphenyltetrazolium chloride staining. Myocardial expression of hypoxia inducible factor (HIF)-1 $\alpha$ and phosphorylated p38 mitogen-activated protein kinase (P-p38 MAPK) protein was measured using western blotting. The results demonstrated that HMGB1 significantly decreased serum levels of cTnI, IL- 6 and TNF- $\alpha$ and myocardial IS in $\mathrm{I} / \mathrm{R}$ rats compared with the sham group (all $\mathrm{P}<0.05$ ). HMGB1 also significantly decreased and increased myocardial levels of MDA and SOD, respectively (both $\mathrm{P}<0.05$ ). HMGB1 significantly increased myocardial expression of HIF-1 $\alpha$ and decreased expression of P-p38 MAPK following I/R
\end{abstract}

Correspondence to: Professor Heng-Chen Yao or Professor De-Yong Zhang, Department of Cardiology, Liaocheng People's Hospital Affiliated to Shandong University and Clinical School of Taishan Medical University, 67 Dongchang West Road, Liaocheng, Shandong 252000, P.R. China

E-mail: yaohc66@126.com

E-mail: zhdyde@sina.com

*Contributed equally

Key words: high mobility group box 1 protein, acute myocardial ischemia, ischemia reperfusion injury, hypoxia inducible factor $1 \alpha$, p38 mitogen-activated protein kinase, rats (both $\mathrm{P}<0.05$ ). These effects of HMGB1 occurred in a dosedependent manner. The results of the current study indicate that the cardioprotective effects of intravenous HMGB1 are associated with increased myocardial expression of HIF-1 $\alpha$ via inhibition of P-p38 MAPK expression, leading to inhibition of the P-p38 MAPK signaling pathway.

\section{Introduction}

Acute myocardial infarction (MI) is a leading cause of mortality and morbidity worldwide. When acute MI occurs, the rapid restoration of coronary artery blood flow via thrombolytic therapy or percutaneous coronary intervention is essential. However, reperfusion itself can lead to myocardial injury and an inflammatory response, which is called ischemia reperfusion (I/R) injury (1). Therefore, attenuating myocardial $\mathrm{I} / \mathrm{R}$ injury is important in the treatment of acute MI.

Hypoxia inducible factor (HIF)- $1 \alpha$ is an important transcription factor that serves an essential role in cellular adaption to conditions of hypoxia and ischemia, which enables cells to differentiate and survive under low oxygen conditions (2). Furthermore, HIF-1 $\alpha$ can restore oxygen homeostasis through the induction of glycolysis, erythropoiesis and angiogenesis (3). A previous study by our group demonstrated that increased myocardial expression of HIF-1 $\alpha$ is associated with cardioprotection against I/R injury (4). Therefore, increasing myocardial expression of HIF-1 $\alpha$ may attenuate myocardial injury following myocardial I/R.

High mobility group box 1 protein (HMGB1) is widely expressed in various tissues, inclduing the liver, brain, spleen, lung, heart and kidney, and can induce the production of proinflammatory cytokines, including tumor necrosis factor (TNF)- $\alpha$ and interleukin (IL)-6, in addition to acting as a proinflmmatory cytokine itself (5). HMGB1 serves a role in numerous cardiovascular diseases, inclduing atherosclerosis, myocardial I/R injury, heart failure and MI (6-10). Extracellular HMGB1 can recognize tissue damage and initiate reparative responses, in addition to participating in the pathogenesis of inflammation and enhancing myocardial I/R injury $(11,12)$.

p38 mitogen-activated protein kinase (p38 MAPK) serves a role in the regulation of various cellular functions. 
Phosphorylated p38 MAPK (P-p38 MAPK) is the active form of p38 MAKP. Inhibition of p38 MAPK activity can protect the heart from I/R injury (13). However, the association between p38 MAPK and HMGB1 in myocardial I/R injury is not yet clear.

Accumulating evidence (14-16) has demonstrated that the administration of HMGB1 after MI or acute global I/R improves left ventricular function via cardiomyocyte regeneration. Our group recently reported that intravenous HMGB1 protect the heart from I/R injury (17). However, a previous study identified that increasing the dose of HMGB1 did not further recover heart function, although it did inhibit inflammatory reactions $(18)$. The majority of previous studies $(15,16)$ administered HMGB1 via direct intramyocardial injection in various animal models.

Whether the cardioprotective effects of intravenous infusion of HMGB1 on myocardial I/R injury are associated with the myocardial expression of HIF- $1 \alpha$ remains unclear. Furthermore, the underlying molecular mechanisms by which intravenous HMGB1 protects the heart from I/R injury remain to be identified. Thus, the present study aimed to evaluate the effect of HMGB1 pretreatment on the myocardial expression of HIF-1 $\alpha$ and investigate the underlying mechanisms of this effect in a rat model.

\section{Materials and methods}

Animal groups. All animal procedures were performed according to the Guide for the Care and Use of Laboratory Animals published by the National Institutes of Health (19), and were approved by the Institutional Review Board of Liaocheng People's Hospital (Liaocheng, China). The rats were housed in a temperature controlled room (temperature, $22 \pm 1^{\circ} \mathrm{C}$ ) under a $12 \mathrm{~h} \mathrm{light/dark} \mathrm{cycle} \mathrm{with} \mathrm{free} \mathrm{access} \mathrm{to} \mathrm{food} \mathrm{and} \mathrm{water.} \mathrm{Male}$ Wistar rats, $(n=50$; weight, 250-300 g; aged 5-11 weeks) were provided by Shandong Lukang Pharmaceutical Co.,Ltd.(Jining, China). The rats were divided into five groups ( $n=10 /$ group) as follows: i) Sham operation group (sham; administered $0.5 \mathrm{ml}$ normal saline intravenously only); ii) I/R group (administered $0.5 \mathrm{ml}$ normal saline intravenously; other treatment described below); iii) HMGB50 group (50 ng/kg recombinant HMGB1 administered intravenously $30 \mathrm{~min}$ before ischemia; the recombinant HMGB1 was purchased in Sino Biological Inc. (Beijing, China; 10326-H08H-50); iv) HMGB100 group (100 $\mathrm{ng} / \mathrm{kg}$ recombinant HMGB1 administered intravenously $30 \mathrm{~min}$ before ischemia); and v) HMGB200 group (200 ng/kg recombinant HMGB1 administered intravenously $30 \mathrm{~min}$ before ischemia). All the HMGB groups underwent the process of I/R.

Animal model of $I / R$. The rat I/R model was established according to the method previously reported by our group (20). Briefly, after anesthesia with sodium pentobarbital (60 mg/kg intraperitoneally), the rats were artificially ventilated ( 55 breaths $/ \mathrm{min}$ ). A thermal pad was used to maintain the rat's body temperature at $37 \pm 0.5^{\circ} \mathrm{C}$. The rats then underwent total ligation of the left anterior descending coronary artery (LAD) for $30 \mathrm{~min}$ and subsequent reperfusion for $180 \mathrm{~min}$. Electrocardiography was used to record changes in the heart rate and rhythm. The LADs of rats in the sham group were not occluded, with only a suture placed at the origin of the LAD.

Biochemical analysis. Blood samples were collected from the femoral vein and centrifuged at $1000 \mathrm{x} \mathrm{g}$ for $10 \mathrm{~min}$ at $4^{\circ} \mathrm{C}$, and the serum obtained was stored at $-80^{\circ} \mathrm{C}$ until required. Serum cardiac troponin I (cTnI), TNF- $\alpha$ and IL-6 levels were determined using ELISA kits (cTnI, KL15219; Shanghai Kanglang Biotechnology Co., Ltd., Shanghai, China) (TNF- $\alpha$, 69-30484; IL-6, 69-30490; Wuhan Moschak Biotechnology Co., Ltd., Wuhan, China).

Measurement of myocardial malondialdehyde (MDA) and superoxide dismutase (SOD) levels. The rats were sacrificed by decapitation after anesthetization via intraperitoneal injection of phenobarbital $(60 \mathrm{mg} / \mathrm{kg})$. The hearts were harvested and washed with normal saline. Ischemic heart tissue $(0.5 \mathrm{~g})$ was then homogenized at $0-4^{\circ} \mathrm{C}$ and the homogenate was centrifugated at $1,200 \times \mathrm{g}$ for $30 \mathrm{~min}$ at $4^{\circ} \mathrm{C}$. The supernatant was obtained and stored at $-80^{\circ} \mathrm{C}$ until required. The thiobarbituric acid reactive substances assay was used to determine the level of MDA and the xanthine oxide method was used to determine SOD activity. The MDA assay kit (A003-1) and SOD assay kit (A001-3) were purchased from NanJing JianCheng Bioengineering Institute (Nanjing, China) and used according to the manufacturer's protocol.

Assessment of infarction size (IS). IS was assessed by Evans blue dye and 2,3,5-triphenyltetrazolium chloride (TTC) staining methods as described previously (21). Briefly, after reperfusion, the LAD was occluded again and $1 \mathrm{ml} 2.0 \%$ Evans blue dye was injected intravenously. The heart was excised, rinsed and the atria were trimmed off. The left ventricle was sliced horizontally into five slices from apex to base. The thickness of the slices were $\sim 2 \mathrm{~mm}$. The sections were incubated in $1 \%$ TTC for $15 \mathrm{~min}$ at $37^{\circ} \mathrm{C}$. Impaired, infarcted and normal myocardium was stained red, white and blue, respectively. The borders of the infarcted, ischemic and nonischemic areas of the heart on the images captured were traced and measured using Image-Pro Plus software (version 3.0; Media Cybernetics, Inc., Rockville, MD, USA). IS was expressed as a percentage of the risk area volume as follows: IS $(\%)=$ IS/risk area. Risk area referred to the myocardium that was stained red by TTC.

Assessment of left ventricular function. A total of 4 weeks following I/R, all rats underwent a transthoracic echocardiography using a Philips Sosnos 7500 ultrasound machine (Philips Healthcare, Amsterdam, The Netherlands; probe frequency $10 \mathrm{MHz}$ ). Left ventricular ejection fraction (LVEF), left ventricular end diastolic diameter (LVEDD) and left ventricular fractional shortening (LVFS) were measured.

Western blotting for HIF-1 $\alpha$ and P-p38MAPK. Expression of HIF-1 $\alpha$ and P-p38MAPK protein was determined using western blotting. The rats were sacrificed by decapitation following anesthetization via intraperitoneal injection of phenobarbital (Tianjin Jinyao Pharmaceutical Co., Ltd., Tianjing, China; $60 \mathrm{mg} / \mathrm{kg}$ ). The hearts were harvested and washed with normal saline. Ischemic heart tissue $(0.5 \mathrm{~g})$ was then homogenized at 
$0-4^{\circ} \mathrm{C}$. Homogenate were centrifuged at $780 \times \mathrm{g}$ at $4^{\circ} \mathrm{C}$. The bicinchoninic acid protein assay kit (Sigma-Aldrich; Merck KGaA, Darmstadt, Germany) was used to determine protein levels according to the manufacturer's protocol. Proteins (50 $\mu \mathrm{g} /$ lane) were separated via SDS-PAGE (10\% separation gel, $5 \%$ spacer gel) and transferred onto polyvinylidene fluoride membranes (Bio-Rad Laboratories, Inc., Hercules, CA, USA). The membranes were blocked for $60 \mathrm{~min}$ at room temperature in 5\% non-fat milk in Tris-buffered saline-Tween-20 (TBST). Subsequently, the membranes were incubated with the following primary rabbit polyclonal antibodies overnight at $4^{\circ} \mathrm{C}$ : anti-HIF- $\alpha(1: 2,000 ; 14179)$, anti P-p38 MAPK $(1: 4,000$; 9212) and anti- $\beta$-actin $(1: 5,000 ; 4967$; all Cell Signaling Technology, Inc., Danvers, MA, USA). The membranes were then incubated with IRDye $680{ }^{\circledR}$ goat anti-rabbit IgG secondary antibodies (1:2,000; 926-68029; LI-COR Bioscience, Lincoln, NE, USA) at room temperature for $120 \mathrm{~min}$ after washing with TBST. Protein bands were visualized using enhanced chemiluminescence and the Fluor-S ${ }^{\mathrm{TM}}$ gel imaging system (version no. 170-8195; Bio-Rad Laboratories, Inc.). Images of every protein band were captured and the software was used to calculate the density of every protein band. The quantity of HIF-1 $\alpha$ protein was expressed relative to $\beta$-actin expression. P-p38 MAPK protein was expressed as a ratio to p38 MAPK expression.

Statistical analysis. Data are expressed as the mean \pm standard deviation. SAS software (version 6.121; SAS Institute, Inc., Cary, NC, USA) was used to analyze the data. The statistical significance of differences in the mean between groups was determined by one-way analysis of the variance. $\mathrm{P}<0.05$ was considered to indicate a statistically significant difference.

\section{Results}

HMGB1 pretreatment decreases serum levels of cTnI, TNF- $\alpha$ and IL-6 following I/R. As presented in Table I, serum c-TnI, TNF- $\alpha$ and IL-6 levels in the I/R group were significantly higher compared with those of the sham group (all $\mathrm{P}<0.01$ ). Serum c-TnI, TNF- $\alpha$ and IL-6 levels in the HMGB100 and HMGB200 groups were significantly lower compared with those in the I/R group in a dose-dependent manner (all $\mathrm{P}<0.05$; Table I). Levels of c-TnI, TNF- $\alpha$ and IL-6 in the HMGB50 group also decreased compared with the I/R group, but statistical levels were not reached (Table I).

HMGB1 pretreatment increases $M D A$ and decreases SOD levels after $I / R$. After I/R, MDA levels were significantly higher and SOD levels were significantly lower in the I/R group compared with the sham group (all $\mathrm{P}<0.01$; Table I). The $\mathrm{I} / \mathrm{R}$-induced increase in MDA and reduction in SOD levels were significantly inhibited by 100 and $200 \mathrm{ng} / \mathrm{kg}$ HMGB1 pretreatment $(\mathrm{P}<0.01$ vs. the I/R group; Table I). Furthermore, this effect occurred in a dose-dependent manner (HMGB100 vs. HMGB50, $\mathrm{P}<0.05$; HMGB200 vs. HMGB100, $\mathrm{P}<0.01$; Table I).

IS after I/R is decreased by HMGBl pretreatment. TTC staining was used to detect the infarcted area. IS was significantly higher in the I/R group compared with that in the sham group ( $\mathrm{P}<0.01$; Table I and Fig. 1). IS in the three HMGB1 treated groups were significantly decreased compared the I/R group (all $\mathrm{P}<0.05$; Table I and Fig. 1). Furthermore, ISs in the HMGB200 group was significantly decreased compared with the HMGB100 and HMGB50 groups (both $\mathrm{P}<0.05$; Table I and Fig. 1), indicating that the reduction in IS caused by HMGB1 was dose-dependent.

HMGB1 pretreatment increases LVEF and LVFS, and decreases $L V E D D$ after $I / R$. As presented in Table II, LVEF and LVFS decreased significantly while LVEDD increased significantly in the I/R group compared with the sham group (all $\mathrm{P}<0.01$ ). Compared with the I/R group, LVEF and LVFS in the HMGB100 and HMGB200 groups were increased significantly, while LVEDD was significantly reduced (all $\mathrm{P}<0.05$; Table II).

HMGB1 pretreatment increases HIF-1 $\alpha$ and decreases $P$-p38 $M A P K$ myocardial protein expression after $I / R$. HIF-1 $\alpha$ protein expression in the I/R group was significantly increased compared with that in the sham group ( $\mathrm{P}<0.01$; Fig. 2). HMGB1 pretreatment (100 and $200 \mathrm{ng} / \mathrm{kg}$ ) further significantly increased the expression of HIF-1 $\alpha$ protein compared with the I/R group (both $\mathrm{P}<0.01$; Fig. 2). Similarly to the changes observed in IS, myocardial expression of HIF-1 $\alpha$ protein in the HMGB200 group was significantly increased compared with the HMGB50 $(\mathrm{P}<0.01)$ and HMGB100 $(\mathrm{P}<0.05)$ groups (Fig. 2).

Expression of P-p38 MAPK protein in the I/R group was significantly increased compared with the sham group $(\mathrm{P}<0.01$; Fig. 3). The HMGB100 and HMGB200 groups had a significantly decreased expression of P-p38 MAPK protein compared with the I/R group (both $\mathrm{P}<0.05$; Fig. 3 ). Furthermore, myocardial expression of the P-p38 MAPK protein in the HMGB200 group was significantly decreased compared with the HMGB50 $(\mathrm{P}<0.01)$ and HMGB100 $(\mathrm{P}<0.05)$ groups (Fig. 3).

\section{Discussion}

The present study identified the following: i) Myocardial expression of HIF-1 $\alpha$ was increased significantly in I/R rats compared with the sham group; ii) HMGB1 could significantly reduce IS, inhibit oxidative stress and increase myocardial expression of HIF-1 $\alpha$; and iii) HMGB1 reduced the expression of P-p38 MAPK. These results suggest that HMGB1 protects the myocardium from I/R injury through increasing HIF-1 $\alpha$ protein expression, which may be contributed to its antioxidative and anti-inflammatory properties, and through decreasing P-p38 MAPK expression.

Previous studies have demonstrated that intramyocardial injection of HMGB1 can reduce local myocardial inflammation, reduce collagen volume fraction, reduce myocardial remodeling and improve cardiac function in animal MI models (22-25). However, the effect of intravenous HMGB1 on myocardial I/R injury remains unclear. cTnI is a biomarker of cardiac injury. In the present study, the effects of three concentrations of intravenous HMGB1 on I/R injury were investigated. Serum cTnI levels in the HMGB200 group were significantly reduced compared with the HMGB50 and HMGB100 groups, 
Table I. Effect of HMGB1 pretreatment of IL-6, TNF- $\alpha$, cTnI, SOD and MDA and IS after I/R.

\begin{tabular}{lcccrr}
\hline & \multicolumn{5}{c}{ Group } \\
\cline { 2 - 6 } Variable & Sham & I/R & HMGB50 & HMGB100 & HMGB200 \\
\hline IL-6 $(\mathrm{pg} / \mathrm{ml})$ & $149.39 \pm 14.02$ & $398.23 \pm 17.15^{\mathrm{a}}$ & $302.48 \pm 24.22^{\mathrm{a}}$ & $276.68 \pm 19.05^{\mathrm{a}-\mathrm{c}}$ & $219.78 \pm 20.53^{\mathrm{a}-\mathrm{d}}$ \\
$\mathrm{TNF}-\alpha(\mathrm{pg} / \mathrm{ml})$ & $20.88 \pm 6.14$ & $69.17 \pm 4.56^{\mathrm{a}}$ & $58.43 \pm 3.57^{\mathrm{a}}$ & $50.16 \pm 2.99^{\mathrm{a}-\mathrm{c}}$ & $43.64 \pm 2.01^{\mathrm{a}-\mathrm{d}}$ \\
$\mathrm{cTnI}(\mu \mathrm{g} / \mathrm{l})$ & $0.13 \pm 0.12$ & $75.87 \pm 7.71^{\mathrm{a}}$ & $69.43 \pm 5.17^{\mathrm{a}}$ & $60.19 \pm 5.71^{\mathrm{a}-\mathrm{c}}$ & $49.36 \pm 5.08^{\mathrm{a}-\mathrm{d}}$ \\
SOD $(\mathrm{U} / \mathrm{mg})$ & $138.9 \pm 29.70$ & $68.91 \pm 21.90^{\mathrm{a}}$ & $87.32 \pm 31.60^{\mathrm{a}}$ & $98.01 \pm 6.37^{\mathrm{a}-\mathrm{c}}$ & $123.89 \pm 8.33^{\mathrm{a}-\mathrm{d}}$ \\
MDA $(\mathrm{nmol} / \mathrm{mg}$ & $2.94 \pm 0.13$ & $9.78 \pm 0.34^{\mathrm{a}}$ & $6.92 \pm 0.41^{\mathrm{a}}$ & $6.19 \pm 0.26^{\mathrm{a}-\mathrm{c}}$ & $3.47 \pm 0.25^{\mathrm{a}-\mathrm{d}}$ \\
IS $(\%)$ & $0.00 \pm 0.00$ & $69.73 \pm 3.88^{\mathrm{a}}$ & $55.17 \pm 3.39^{\mathrm{a}}$ & $44.39 \pm 4.59^{\mathrm{a}-\mathrm{c}}$ & $19.71 \pm 5.14^{\mathrm{a}-\mathrm{d}}$ \\
\hline
\end{tabular}

I/R, ischemia/reperfusion; HMGB1, high mobility group box 1 protein; IL-6, interleukin 6; TNF- $\alpha$, tumor necrosis factor $\alpha$; cTnI, cardiac troponin I; SOD, superoxide dismutase; MDA, malondialdehyde; IS, infarction size. ${ }^{\mathrm{a}} \mathrm{P}<0.01 \mathrm{vs}$. the sham group; ${ }^{\text {b }} \mathrm{P}<0.05 \mathrm{vs}$. the I/R group; ${ }^{\mathrm{c}} \mathrm{P}<0.05$ vs. the HMGB50 group; ${ }^{\mathrm{d}} \mathrm{P}<0.05$ vs. the HMGB100 group.

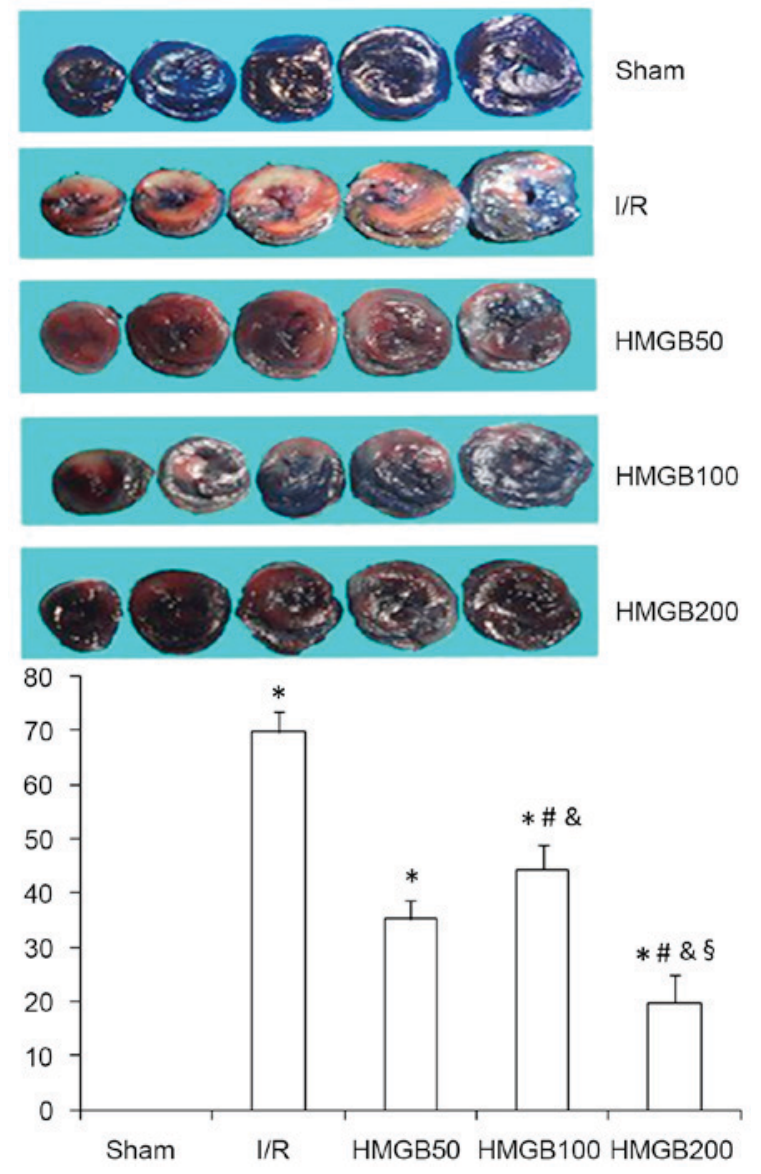

Figure 1. HMGB1 pretreatment decreases infarction size after I/R. I/R ischemia/reperfusion; HMGB1, high mobility group box 1 protein. ${ }^{*} \mathrm{P}<0.01$ vs. the sham group; ${ }^{\#} \mathrm{P}<0.01$ vs. the $\mathrm{I} / \mathrm{R}$ group; ${ }^{\circledR} \mathrm{P}<0.01$ vs. the HMGB50 group; ${ }^{\S} \mathrm{P}<0.05$ vs. the $\mathrm{HMGB} 100$ group.

which suggests that the cardioprotective effects of intravenous HMGB1 following I/R occur in a dose-dependent manner. In addition, the results of the present study demonstrated that intravenous HMGB1 increasesd LVEF and LVFS, and reduced LVEDD. Furthermore, HMGB1 reduced myocardial IS. These results suggest that HMGB1 administered intravenously may protect the heart against $\mathrm{I} / \mathrm{R}$ injury and improve cardiac function. However, the underlying molecular mechanism of this effect remains unclear.

TNF- $\alpha$ and IL- 6 are proinflammatory cytokines are associated with I/R injury. TNF- $\alpha$ enhances the inflammatory cascade by increasing the expression of other proinflammatory cytokines, including IL-6 (26). In addition, TNF- $\alpha$ can cause cardiomyocyte apoptosis and is associated with ventricular remodeling (27). The results of the current study demonstrated that myocardial I/R increased serum levels of TNF- $\alpha$ and IL-6, and that HMGB1 pretreatment reduced this increase. Thus, the inhibition of proinflammatory cytokines, including TNF- $\alpha$ and IL-6, may contribute to the cardioprotective effects of HMGB1.

Previous studies have demonstrated that myocardial I/R injury is associated with the increased generation of reactive oxygen species (ROS) and thus oxidative stress (28). ROS-mediated myocardiocyte apoptosis and necrosis may be a determinant of IS (29). SOD and MDA levels are frequently used to evaluate free radical metabolism, which is a component of the process of oxidative stress. SOD levels reflect the cellular capacity for scavenging/quenching free radicals. In the current study, SOD levels were significantly decreased and MDA levels were significantly increased in the heart tissue of the I/R group compared with the sham group. HMGB1 increased SOD and decreased MDA levels in the myocardium in a dose-dependent manner, which was associated with a decrease in IS. These results indicate that HMGB1 also exerts its cardioprotective effects via acting as an antioxidant.

HIF-1 $\alpha$ can regulate the cellular response of hypoxia. HIF-1 $\alpha$ expression is increased in various organs and tissues during ischemia, including the nervous system (30), and myocardium $(4,31)$. HIF-1 $\alpha$ is required for the remote ischemic preconditioning of the heart (32). Postconditioning can decrease IS, reduce apoptosis and upregulate HIF-1 $\alpha$ (33). The upregulation of HIF-1 $\alpha$ can in turn enhance cardioprotection from ischemic postconditioning (34). HIF-1 $\alpha$ thus protects against myocardial I/R injury (35). A partial deficiency in HIF-1 $\alpha$ can result in a complete loss of cardioprotection against I/R injury (36). Our group previously reported that basic fibroblast growth factor could enhance the myocardial expression of HIF-1 $\alpha$ mRNA, thus decreasing IS and improving left 
Table II. Effect of HMGB1 on cardiac function after I/R.

\begin{tabular}{lrrrrr}
\hline & \multicolumn{5}{c}{ Group } \\
\cline { 2 - 6 } Variable & \multicolumn{1}{c}{ Sham } & \multicolumn{1}{c}{ I/R } & \multicolumn{1}{c}{ HMGB50 } & HMGB100 & HMGB200 \\
\hline LVEDD $(\mathrm{mm})$ & $4.04 \pm 0.28$ & $6.61 \pm 0.85^{\mathrm{a}}$ & $6.21 \pm 1.03^{\mathrm{a}}$ & $5.68 \pm 1.25^{\mathrm{a}-\mathrm{c}}$ & $5.07 \pm 0.64^{\mathrm{a}-\mathrm{d}}$ \\
LVFS $(\%)$ & $37.9 \pm 2.28$ & $18.23 \pm 1.85^{\mathrm{a}}$ & $22.13 \pm 1.43^{\mathrm{a}}$ & $27.47 \pm 2.35^{\mathrm{a}-\mathrm{c}}$ & $32.07 \pm 2.64^{\mathrm{a}-\mathrm{d}}$ \\
LVEF $(\%)$ & $79.90 \pm 7.13$ & $46.68 \pm 3.92^{\mathrm{a}}$ & $45.87 \pm 6.22^{\mathrm{a}}$ & $65.49 \pm 5.54^{\mathrm{a}-\mathrm{c}}$ & $72.39 \pm 4.98^{\mathrm{a}-\mathrm{d}}$ \\
\hline
\end{tabular}

I/R, ischemia/reperfusion; HMGB, high mobility group box 1 protein; LVEDD, left ventricular end diastolic diameter; LVFS, left ventricular fractional shortening; $\mathrm{LVEF}$, left ventricular ejection fraction. ${ }^{\mathrm{a}} \mathrm{P}<0.01 \mathrm{vs}$. the sham group; ${ }^{\mathrm{b}} \mathrm{P}<0.05 \mathrm{vs}$. the $\mathrm{I} / \mathrm{R}$ group; ${ }^{\mathrm{C}} \mathrm{P}<0.05 \mathrm{vs}$. the $\mathrm{HMGB} 50$ group; ${ }^{\mathrm{d}} \mathrm{P}<0.05$ vs. the HMGB100 group.

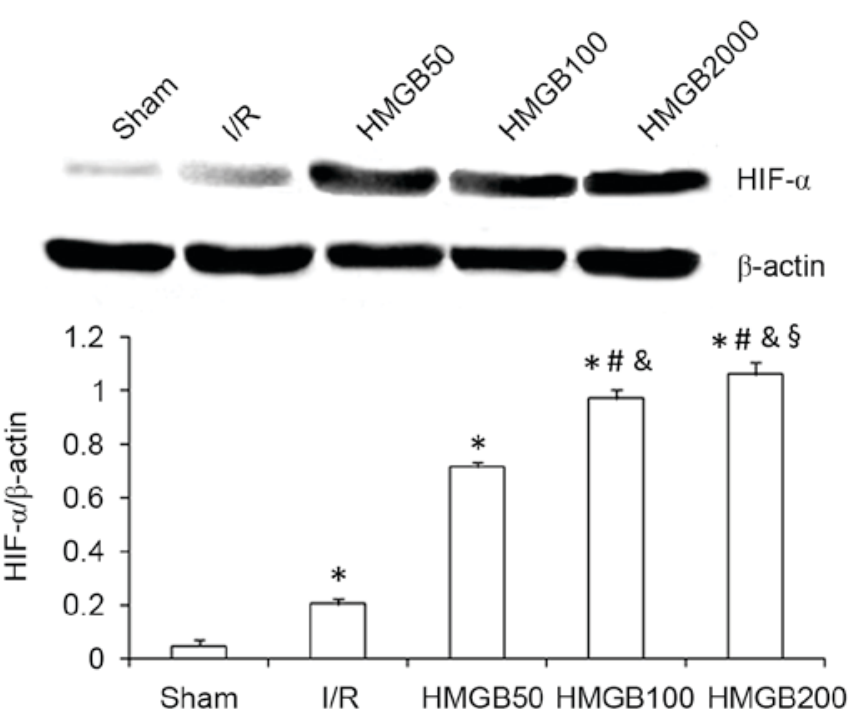

Figure 2. HMGB1 pretreatment increases myocardial HIF-1 $\alpha$ protein expression after I/R. Western blot and quantification for HIF-1 $\alpha$ protein expression. I/R, ischemia/reperfusion; HMGB1, high mobility group box 1 protein; HIF-1 $\alpha$, hypoxia inducible factor- $1 \alpha$. ${ }^{*} \mathrm{P}<0.01$ vs. the sham group; ${ }^{~} \mathrm{P}<0.01$ vs. the I/R group; ${ }^{\circledR} \mathrm{P}<0.01$ vs. the HMGB50 group; ${ }^{\circledR} \mathrm{P}<0.05$ vs. the HMGB100 group.

ventricular function in rats following acute MI (4). Similarly, the current study demonstrated that I/R significantly increased myocardial expression of HIF-1 $\alpha$ and that this expression was further elevated by HMGB1 pretreatment in a dose-dependent manner. This increase in HIF-1 $\alpha$ expression was associated with inhibition of I/R-induced myocardial injury.

To the best of our knowledge, the present study is the first report that HIF-1 $\alpha$ may be associated with the cardioprotective effects of intravenous HMGB1. However, the underlying molecular mechanisms of how HIF-1 $\alpha$ facilitates the cardioprotective effects of HMGB1 following I/R are unclear. A previous study revealed that the upregulation of HIF-1 $\alpha$ was one of the first responses to myocardial I/R injury at the molecular level (37). HIF-1 $\alpha$ activation confers protective effects against I/R injury through enhancing the expression of genes associated with glycolysis, cell survival, apoptosis, mitochondrial function, glucose metabolism and resistance to oxidative stress (38). HIF-1 $\alpha$ activation also

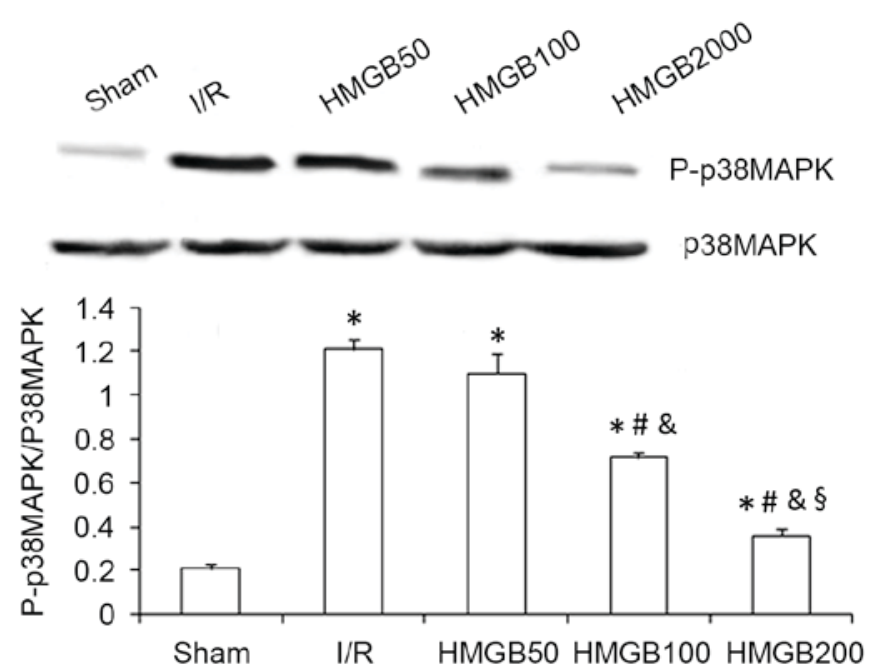

Figure 3. HMGB1 pretreatment decreases myocardial P-p38 MAPK protein expression after I/R. Western blot and quantification for P-p38 MAPK protein expression. I/R, ischemia/reperfusion; HMGB, high mobility group box 1 protein; P-p38 MAPK, phosphorylated p38 mitogen-activated protein kinase. ${ }^{*} \mathrm{P}<0.01$ vs. the sham group; ${ }^{\#} \mathrm{P}<0.05$ vs. the $\mathrm{I} / \mathrm{R}$ group; ${ }^{\circledR} \mathrm{P}<0.01$ vs. the HMGB50 group; ${ }^{\circledR} \mathrm{P}<0.05$ vs. the HMGB100 group.

results in activation of the inducible nitric oxide synthase signaling pathway, which further stabilizes HIF-1 $\alpha$ (39). The stabilization of HIF-1 $\alpha$ under normoxic conditions protects the heart from acute I/R injury via triggering angiogenesis and preserving cardiac function $(36,40)$. A recent study suggested that the acute stabilization of HIF-1 $\alpha$ through pharmacological or genetic mechanisms protected the heart from acute IR injury by increasing aerobic glycolysis, inhibiting mitochondrial oxidative stress, activating hexokinase II and inhibiting mitochondrial permeability (41).

p38 MAPK serves a role in numerous biological process, including cell migration and death. A recent study demonstrated that licochalcone D treatment enhanced cardiac function, suppressed cardiac injury, reduced levels of proinflammatory factors and enhanced the antioxidant capacity of myocardial tissue following I/R (37). This effect was associated with inhibition of the p38 MAPK signaling pathway (42). p38 MAPK inhibition also protects mitochondria from I/R 
injury (43), and improves cardiac function and ventricular remodeling following $\mathrm{I} / \mathrm{R}$ (44). In the present study, the myocardial expression of P-p38 MAPK in the I/R group was significantly higher compared with that in the sham group, suggesting that myocardial ischemia increases P-p38 MAPK expression. The expression of P-p38 MAPK was decreased by HMGB1 treatment in a dose-dependent manner. These results indicate that intravenous HMGB1 protects the heart from I/R injury via inhibition of P-p38 MAPK expression in ischemic myocardium.

A limitation of the current study was the lack of a p38 MAPK inhibitor to confirm the role of p38 MAPK on the cardioprotective effects of HMGB1 following I/R. Thus, further studies using a 38 MAPK inhibitor are required to confirm the underlying mechanism by which intravenous HMGB1 protects the heart from I/R injury. In addition, HMGB1 was administered 30 min prior to the ligation of the coronary arteries in the present study. In clinical settings, drugs are typically administered several $\mathrm{h}$ after the onset of ischemia. Therefore, the effect of HMGB1 given several $\mathrm{h}$ after the ligation of the coronary arteries requires further study in order to more closely emulate the clinical treatment of ischemia.

In conclusion, the results of the present study on an acute $\mathrm{I} / \mathrm{R}$ rat model suggested that intravenous HMGB1 was associated with a reduced IS, inhibition of oxidative stress, improvement of cardiac function, increased HIF-1 $\alpha$ expression and reduced expression of P-p38 MAPK. These results suggest that intravenous HMGB1 may exert its cardioprotective effect via upregulating myocardial HIF-1 $\alpha$ protein expression, at least in part, via the inhibition of the P-p38 MAPK signaling pathway.

\section{Acknowledgements}

The present study was supported by the Natural Science Foundation of Shandong Province (grant nos. ZR2013HL017, ZR2016HM49 and ZR2016HB73), the Natural Science Foundation of Liaocheng City (grant no. 2012NS13), and the Science and Technology Development Project of Liaocheng City (grant no. 2014GJH26).

\section{References}

1. Eltzschig HK and Eckle T: Ischemia and reperfusion-from mechanism to translation. Nat Med 17: 1391-1401, 2011.

2. Maes C, Carmeliet G and Schipani E: Hypoxia-driven pathways in bone development, regeneration and disease. Nat Rev Rheumatol 8: 358-366, 2012.

3. van de Sluis B, Groot AJ, Vermeulen J, van der Wall E, van Diest PJ, Wijmenga C, Klomp LW and Vooijs M: COMMD1 Promotes pVHL and O2-Independent Proteolysis of HIF-1alpha via HSP90/70. PLoS One 4: e7332, 2009.

4. Yao HC, Liu T, Meng XY, Han QF, Zhang M and Wang LX: Effect of basic fibroblast growth factor on the myocardial expression of hypoxia-inducible factor- $1 \alpha$ and vascular endothelial growth factor following acute myocardial infarctio. Heart Lung Circ 22: 946-951, 2013.

5. Li J, Kokkola R, Tabibzadeh S, Yang R, Ochani M, Qiang X, Harris HE, Czura CJ, Wang H, Ulloa L, et al: Structural basis for the proinflammatory cytokine activity of high mobility group box 1. Mol Med 9: 37-45, 2003.

6. Yan XX, Lu L, Peng WH, Wang LJ, Zhang Q, Zhang RY, Chen QJ and Shen WF: Increased serum HMGB1 level is associated with coronary artery disease in nondiabetic and type 2 diabetic patients. Atherosclerosis 205: 544-548, 2009.
7. Kohno T, Anzai T, Naito K, Miyasho T, Okamoto M, Yokota H, Yamada S, Maekawa Y, Takahashi T, Yoshikawa T, et al: Role of high-mobility group box 1 protein in post-infarction healing process and left ventricular remodelling. Cardiovasc Res 81: 565-573, 2009.

8. Avalos AM, Kiefer K, Tian J, Christensen S, Shlomchik M, Coyle AJ and Marshak-Rothstein A: RAGE-independent autoreactive $\mathrm{B}$ cell activation in response to chromatin and HMGB1/DNA immune complexes. Autoimmunity 43: 103-110, 2010.

9. Ding HS and Yang J: High mobility group box-1 and cardiovascular diseases. Saudi Med J 31: 486-489, 2010.

10. Yao HC, Zhao AP, Han QF, Wu L, Yao DK and Wang LX: Correlation between serum high-mobility group box-1 levels and high-sensitivity C-reactive protein and troponin I in patients with coronary artery disease. Exp Ther Med 6: 121-124, 2013.

11. Ulloa L and Messmer D: High-mobility group box 1 (HMGB1) protein: Friend and foe. Cytokine Growth Factor Rev 17: 189-201, 2006.

12. Xu H, Yao Y, Su Z, Yang Y, Kao R, Martin CM and Rui T: Endogenous HMGB1 contributes to ischemia-reperfusion-induced myocardial apoptosis by potentiating the effect of TNF-\&alpha;/JNK. Am J Physiol Heart Circ Physiol 300: H913-H921, 2011.

13. Ran K, Gong ZX, Yang DL, Chang YT, Duan KM and Ou YW: Effect of morphine preconditioning in the delayed phase on the expression of p38 mitogen-activated protein kinase in a rabbit model of myocardial ischemia-reperfusion injury. Genet Mol Res 14: 6642-6648, 2015.

14. Limana F, Germani A, Zacheo A, Kajstura J, Di Carlo A, Borsellino G, Leoni O, Palumbo R, Battistini L, Rastaldo R, et al: Exogenous high-mobility group box 1 protein induces myocardial regeneration after infarction via enhanced cardiac C-kit+ cell proliferation and differentiation. Circ Res 97: e73-e83, 2005.

15. Limana F, Esposito G, Fasanaro P, Foglio E, Arcelli D, Voellenkle C, Di Carlo A, Avitabile D, Martelli F, Antonio Russo M, et al: Transcriptional profiling of hmgb1-induced myocardial repair identifies a key role for notch signaling. Mol Ther 21: 1841-1851, 2013

16. Abarbanell AM, Hartley JA, Herrmann JL, Weil BR, Wang Y, Manukyan MC, Poynter JA and Meldrum DR: Exogenous high-mobility group box 1 improves myocardial recovery after acute global ischemia/reperfusion injury. Surgery 149: 329-335, 2011.

17. Zhang DY, Zhang AX, Zhou YH, Wang LH and Yao HC: Protection of intravenous HMGB1 on myocardial ischemia reperfusion injury. Int J Cardiol 184: 280-282, 2015.

18. Biscetti F, Ghirlanda G and Flex A: Therapeutic potential of high mobility group box-1 in ischemic injury and tissue regeneration. Curr Vasc Pharmacol 9: 677-681, 2011.

19. National Research Council: Guide for the Care and Use of Laboratory Animals. 8th edition. The National Academies Press, Washington, DC, 2011.

20. Takahashi K, Fukushima S, Yamahara K, Yashiro K, Shintani Y, Coppen SR, Salem HK, Brouilette SW, Yacoub MH and Suzuki K: Modulated inflammation by injection of high-mobility group box 1 recovers post-infarction chronically failing heart. Circulation 118 (14 Suppl): S106-S114, 2008.

21. Limana F, Esposito G, D'Arcangelo D, Di Carlo A, Romani S, Melillo G, Mangoni A, Bertolami C, Pompilio G, Germani A and Capogrossi MC: HMGB1 attenuates cardiac remodelling in the failing heart via enhanced cardiac regeneration and miR-206-mediated inhibition of TIMP-3. PLoS One 6: e19845, 2011.

22. Yao HC, Yang LJ, Han QF, Wang LH, Wu L, Zhang CY, Tian KL and Zhang M: Postconditioning with simvastatin decreases myocardial injury in rats following acute myocardial ischemia. Exp Ther Med 9: 1166-1170, 2015.

23. Chen M, Huang W, Wang C, Nie H, Li G, Sun T, Yang F, Zhang Y, Shu K, Wang C and Gong Q: High-mobility group box 1 exacerbates $\mathrm{CCl}_{4}$-induced acute liver injury in mice. Clin Immunol 153: 56-63, 2014.

24. Zhou X, Hu X, Xie J, Xu C, Xu W and Jiang H: Exogenous high-mobility group box 1 protein injection improves cardiac function after myocardial infarction: Involvement of Wnt signaling activation. J Biomed Biotechnol 2012: 743879, 2012.

25. He Y, Zhou X, Zheng X and Jiang X: Exogenous high-mobility group box 1 protein prevents postinfarction adverse myocardial remodeling through TGF- $\beta /$ Smad signaling pathway. J Cell Biochem 114: 1634-1641, 2013. 
26. Khimenko PL, Bagby GJ, Fuseler J and Taylor AE: Tumor necrosis factor-alpha in ischemia and reperfusion injury in rat lungs. J Appl Physiol (1985) 85: 2005-2011, 1998.

27. Zhu J, Liu M, Kennedy RH and Liu SJ: TNF-alpha-induced impairment of mitochondrial integrity and apoptosis mediated by caspase- 8 in adult ventricular myocytes. Cytokine 34: 96-105, 2006.

28. Jahangiri A, Leifert WR, Kind KL and McMurchie EJ: Dietary fish oil alters cardiomyocyte $\mathrm{Ca} 2+$ dynamics and antioxidant status. Free Radic Bio Med 40: 1592-1602, 2006.

29. Matsui Y, Takagi H, Qu X, Abdellatif M, Sakoda H, Asano T, Levine B and Sadoshima J: Distinct roles of autophagy in the heart during ischemia and reperfusion: Roles of AMP-activated protein kinase and Beclin 1 in mediating autophagy. Circ Res 100: 914-922, 2007.

30. Rapino C, Bianchi G, Di Giulio C, Centurione L, Cacchio M, Antonucci A and Cataldi A: HIF-lalpha cytoplasmic accumulation is associated with cell death in old rat cerebral cortex exposed to intermittent hypoxia. Aging Cell 4: 177-185, 2005.

31. AI-Salam S and Hashmi S: Galectin-1 in early acute myocardial infarction. PLoS One 9: e86994, 2014.

32. Cai Z, Luo W, Zhan H and Semenza GL: Hypoxia-inducible factor 1 is required for remote ischemic preconditioning of the heart. Proc Natl Acad Sci USA 110: 17462-17467, 2013.

33. Fang Li Q, Xu H, Sun Y, Hu R and Jiang H: Induction of inducible nitric oxide synthase by isoflurane post-conditioning via hypoxia inducible factor- $1 \alpha$ during tolerance against ischemic neuronal injury. Brain Res 1451: 1-9, 2012.

34. Li X, Zhao H, Wu Y, Zhang S, Zhao X, Zhang Y, Wang J, Wang J and Liu H: Up-regulation of hypoxia-inducible factor-1o enhanced the cardioprotective effects of ischemic postconditioning in hyperlipidemic rats. Acta Biochim Biophys Sin (Shanghai) 46: 112-118, 2014.

35. Poynter JA, Manukyan MC, Wang Y, Brewster BD, Herrmann JL, Weil BR, Abarbanell AM and Meldrum DR: Systemic pretreatment with dimethyloxalylglycine increases myocardial HIF-1 $\alpha$ and VEGF production and improves functional recovery after acute ischemia/reperfusion. Surgery 150: 278-283, 2011.

36. Cai Z, Zhong H, Bosch-Marce M, Fox-Talbot K, Wang L, Wei C, Trush MA and Semenza GL: Complete loss of ischaemic preconditioning-induced cardioprotection in mice with partial deficiency of HIF-1 alpha. Cardiovasc Res 77: 463-470, 2008.
37. Adluri RS, Thirunavukkarasu M, Dunna NR, Zhan L, Oriowo B, Takeda K, Sanchez JA, Otani H, Maulik G, Fong GH and Maulik N: Disruption of hypoxia-inducible transcription factor-prolyl hydroxylase domain-1 (PHD-1-/-) attenuates ex vivo myocardial ischemia/reperfusion injury through hypoxia-inducible factor- $1 \alpha$ transcription factor and its target genes in mice. Antioxid Redox Signal 15: 1789-1797, 2011.

38. Ke Q and Costa M: Hypoxia-inducible factor-1 (HIF-1). Mol Pharmacol 70: 1469-1480, 2006.

39. Si J, Wang N, Wang H, Xie J, Yang J, Yi H, Shi Z, Ma J, Wang W, Yang L, et al: HIF-1 $\alpha$ signaling activation by post-ischemia treatment with astragaloside IV attenuates myocardial ischemia-reperfusion injury. PLoS One 9: e107832, 2014.

40. Oriowo B, Thirunavukkarasu M, Selvaraju V, Adluri RS, Zhan L, Takeda K, Fong GH, Sanchez JA and Maulik N: Targeted gene deletion of prolyl hydroxylase domain protein 3 triggers angiogenesis and preserves cardiac function by stabilizing hypoxia inducible factor 1 alpha following myocardial infarction. Curr Pharm Des 20: 1305-1310, 2014.

41. Ong SG, Lee WH, Theodorou L, Kodo K, Lim SY, Shukla DH, Briston T, Kiriakidis S, Ashcroft M, Davidson SM, et al: HIF-1 reduces ischaemia-reperfusion injury in the heart by targeting the mitochondrial permeability transition pore. Cardiovasc Res 104: 24-36, 2014.

42. Yuan X, Niu HT, Wang PL, Lu J, Zhao H, Liu SH, Zheng QS and Li CG: Cardioprotective effect of licochalcone d against myocardial ischemia/reperfusion injury in langendorff-perfused rat hearts. PLoS One 10: e0128375, 2015.

43. Kumphune S, Surinkaew S, Chattipakorn SC and Chattipakorn N: Inhibition of p38 MAPK activation protects cardiac mitochondria from ischemia/reperfusion injury. Pharm Biol 53: 1831-1841, 2015.

44. Wang X, Lv H, Gu Y, Wang X, Cao H, Tang Y, Chen H and Huang C: Protective effect of lycopene on cardiac function and myocardial fibrosis after acute myocardial infarction in rats via the modulation of p38 and MMP-9. J Mol Histol 45: 113-120, 2014. 